\title{
On the calculation of energy produced by a PV grid-connected system
}

\author{
O. Perpiñan \\ ISOFOTON S.A., Montalban 9, 28014 Madrid, Spain* \\ E. Lorenzo \\ Solar Energy Institute, UPM, Ciudad Universitaria, s/n, 28040 Madrid, Spain \\ M.A. Castro \\ Electrical and Computer Engineering Department, UNED, \\ Juan del Rosal, 12, Ciudad Universitaria, 28040 Madrid, Spain
}

\begin{abstract}
This study develops a proposal of method of calculation useful to estimate the energy produced by a PV grid-connected system making use of irradiance-domain integrals and definition of statistical moment. Validation against database of real PV plants performance data shows that acceptable energy estimation can be obtained with first to fourth statistical moments and some basic system parameters. This way, only simple calculations at the reach of pocket calculators, are enough to estimate AC energy.

Keywords: Grid-connected PV systems; Energy production calculation; Solar radiation statistics.
\end{abstract}

\section{INTRODUCTION}

Photovoltaic solar energy is claimed to play a crescent role in the energetic system production [1, 2]. Several public programmes aim to promote this type of energy production by means of subsidies, financing, and mainly with feed-in tariff. These programmes are making PV grid-connected systems attractive for several kinds of investors. As an important consequence, since attractiveness and safeness of these inversions are directly related to energetic performance, the estimation of produced energy is, more than ever, an important issue. It is not difficult to find different computation methods which range from simple equations to complex simulation software obtaining energy values from time-domain integrals [3, 4]. This paper reviews modelling equations of a PV grid-connected system performance. We use an original point of view with irradiance-domain integrals, in the way to a simple but precise method useful for a comprehension of the relevance of different factors.

The structure of the article is as follows: first, modelling equations of a PV grid-connected system performance are shown, both for PV generator and inverter; then energy calculations are developed by means of irradiance-domain integrals, using statistical moments for analytical resolution of equations; validation of this computation method is carried out with two different system performance databases; and finally, discussion about the relevance of statistical moments is provided.

\section{MODELLING EQUATIONS}

\section{A. PV Generator}

DC power delivered by a PV generator is given by

$$
P_{d c}=G_{e f f} \eta_{g} A_{g}
$$

with $G_{e f f}$ as effective incident irradiance, $\eta_{g}$ as the efficiency of the generator and $A_{g}$ as the generator active surface. At STC, equation (1) leads to:

$$
P_{g}^{*}=G^{*} \eta_{g}^{*} A_{g}
$$


where $P_{g}^{*}$ is the rated peak power and $G^{*}=1000 \frac{\mathrm{W}}{\mathrm{m}^{2}}$. Combining equations (1) and (2), $P_{d c}$ is given by:

$$
P_{d c}=P_{g}^{*} \frac{G_{e f f}}{G^{*}} \frac{\eta_{g}}{\eta_{g}^{*}}
$$

The ratio $\frac{\eta_{g}}{\eta_{g}^{*}}$ represents thermal losses, that is, energy losses due to operation cell temperature, $T_{c}$, higher than $T_{c}^{*}=25^{\circ} \mathrm{C}$. This ratio can be related with irradiance and ambient temperature, $T_{a}$, by means of $[5,6]$ :

$$
\begin{aligned}
\frac{\eta_{g}}{\eta_{g}^{*}} & =1-\beta\left(T_{c}-T_{c}^{*}\right) \\
T_{c} & =T_{a}+C_{T} G_{e f f} \\
C_{T} & =\frac{N O C T-20}{0,8 G^{*}}
\end{aligned}
$$

Both $\beta$ and NOCT are technical parameters usually provided by the module manufacturer, as temperature losses coefficient and Nominal Operation Cell Temperature, respectively.

For the purposes of this article, it is useful to refer $P_{d c}$ to the nominal inverter power, $P_{i n v}$, so $p_{i}=\frac{P_{d c}}{P_{i n v}}$. Therefore equation (3) is rewritten as:

$$
p_{i}=F_{d i} \frac{G_{e f f}}{G^{*}}\left[1-\beta\left(T_{c}-25\right)\right]
$$

where: $F_{d i}=\frac{P_{g}^{*}}{P_{i n v}}$.

Equation (7) may be rewritten expanding $T_{c}$ :

$$
p_{i}=G_{e f f}\left\{\frac{F_{d i}}{G^{*}}\left[1-\beta\left(T_{a}-T_{c}^{*}\right)\right]\right\}+G_{e f f}^{2}\left(-\frac{F_{d i}}{G^{*}} \beta C_{T}\right)
$$

and then rearranged as:

$$
p_{i}=A_{1, g} G_{e f f}+A_{2, g} G_{e f f}^{2}
$$

with:

$$
\begin{aligned}
A_{1 g} & =\frac{F_{d i}}{G^{*}}\left[1-\beta\left(T_{a}-T_{c}^{*}\right)\right] \\
A_{2 g} & =-\frac{F_{d i}}{G^{*}} \beta C_{T}
\end{aligned}
$$

\section{B. Inverter}

Inverter efficiency, $\eta_{i n v}$, derives from the ratio between the actual power delivered to the output, $P_{a c}$, and the rated power, $P_{i n v}$. This dependence is commonly described with a function of normalized output power [7]:

$$
\eta_{\text {inv }}=\frac{p_{o}}{p_{o}+k_{0}^{o}+k_{1}^{o} p_{o}+k_{2}^{o} p_{o}^{2}}
$$

where $p_{o}=\frac{P_{a c}}{P_{i n}}$, and $k_{0}^{o}, k_{1}^{o}$ and $k_{2}^{o}$ are characteristic adimensional parameters, which define the electrical behaviour of the inverter. However, for our present purposes, it is more convenient to keep on normalized input power, $p_{i}$, so inverter losses, $p_{L}=\frac{P_{d c}-P_{a c}}{P_{i n v}}$, and inverter efficiency are described as:

$$
\begin{aligned}
\eta_{\text {inv }} & =1-\frac{p_{L}}{p_{i}} \\
p_{L} & =k_{0}^{i}+k_{1}^{i} p_{i}+k_{2}^{i} p_{i}^{2}
\end{aligned}
$$

where $k_{0}^{i}, k_{1}^{i}$ and $k_{2}^{i}$ are also characteristic adimensional parameters of the inverter, which can be obtained from the experimental efficiency curve. It must be pointed up that both input and output parameters have different physical meaning.

The procedure for obtaining $k_{n}^{i}$ is as follows: 
- From experimental data, mean input and output inverter power are calculated around three different working points. We have chosen $p_{i} \in\left\{\begin{array}{lll}0.2 & 0.5 & 0.75\end{array}\right\}$.

$$
\begin{array}{r}
p_{i_{p}}=\left.\overline{p_{i} \mid}\right|_{p_{i}>0.95 \cdot p} ^{p_{i}<1.05 \cdot p} \\
p_{o_{p}}=\left.\overline{p_{o} \mid}\right|_{p_{i}>0.95 \cdot p} ^{p_{i}<1.05 \cdot p}
\end{array}
$$

- With these 6 values of $p_{i}$ and $p_{o}$ a linear system is constructed (eq. 16). The set of inverter coefficients is the solution of this linear system.

$$
\left[\begin{array}{lll}
1 & p_{i_{20}} & p_{i_{20}}^{2} \\
1 & p_{i_{50}} & p_{i_{50}}^{2} \\
1 & p_{i_{75}} & p_{i_{75}}^{2}
\end{array}\right] \cdot\left[\begin{array}{l}
k_{0}^{i} \\
k_{1}^{i} \\
k_{2}^{i}
\end{array}\right]=\left[\begin{array}{l}
p_{i_{20}}-p_{o_{20}} \\
p_{i_{50}}-p_{o_{50}} \\
p_{i_{75}}-p_{o_{75}}
\end{array}\right]
$$

With equation (9) it is possible to rearrange eq. (13) as:

$$
p_{L}=\sum_{n=0}^{4} A_{n, L} G_{e f f}^{n}
$$

where:

$$
\begin{aligned}
& A_{0, L}=k_{0}^{i} \\
& A_{1, L}=k_{1}^{i} A_{1, g} \\
& A_{2, L}=k_{1}^{i} A_{2, g}+k_{2}^{i} A_{1, g}^{2} \\
& A_{3, L}=2 k_{2}^{i} A_{1, g} A_{2, g} \\
& A_{4, L}=k_{2}^{i} A_{2, g}^{2}
\end{aligned}
$$

\section{ENERGY PRODUCTION}

\section{A. Time-domain and irradiance-domain integrals}

The use of time-domain integrals, that is, integration of instantaneous power over a period, $T$, is the most evident method to estimate energy production and also energy losses at a PV system. In practice, this is typically carried out by extending a sum over the hours of a Typical Meteorological Year, and there are several software products aiming to that [8]. However, it is not the best way of computation in terms of algorithm efficiency. For example, two identical values at different times are calculated twice instead of only once and multiplying the result by two.

$$
E_{d c}=P_{i n v} \int_{T} p_{i}(t) d t
$$

Irradiance-domain integrals with the use of probability density functions of effective irradiance, $f_{G_{e f f}}(G)$, represents a different procedure of energy quantification, which provides a more efficient algorithm and additional chances for understanding meteorological influence in the performance of a PV system. So that, DC energy, $E_{d c}$, can be described with:

$$
E_{d c}=P_{i n v} T \int_{G} p_{i}(G) f_{G_{e f f}}(G) d G
$$

and making use of equation (9): 


$$
E_{d c}=P_{i n v} T \int_{G}\left(A_{1, g} G_{e f f}+A_{2, g} G_{e f f}^{2}\right) f_{G_{e f f}}(G) d G
$$

It is possible to find a constant value of ambient temperature equivalent to the integration of diurnal fluctuations of this variable. This mathematical arrangement allows to extract $A_{1, g}$ out of the integral, as expressed with next equation:

$$
A_{1, g}^{y}=\frac{\int_{G} A_{1, g} G_{e f f} f_{G_{e f f}}(G) d G}{\int_{G} G_{e f f} f_{G_{e f f}}(G) d G}
$$

where $A_{1, g}^{y}$ denotes the value of $A_{1, g}$ when a constant value $T_{a}^{y}$ is chosen for ambient temperature in equation (10). Therefore we can write:

$$
E_{d c}=P_{i n v} T\left(A_{1, g}^{y} \int_{G} G_{e f f} f_{G_{e f f}}(G) d G+A_{2, g} \int_{G} G_{e f f}^{2} f_{G_{e f f}}(G) d G\right)
$$

Some authors have found that integration of temperature variations is well approximated by the annual average of daylight ambient temperature $[17,18]$. Moreover, due to the commonly low value of the temperature losses coefficient, $\beta$, the sensitivity of energy production estimation to the value of this constant temperature is very low. Consequently, using a figure around the annual mean of daily temperatures is acceptable. Values for this constant can be easily achieved on the Internet [22] with a good spatial resolution, or using local meteorological atlases (for example, [19]).

In the rest of the article we will notate $A_{1, g} \equiv A_{1, g}^{y}$ and $T_{a} \equiv T_{a}^{y}$.

Similar arrangements can be applied to eq. (17) to get inverter energy losses, $E_{L}$ :

$$
E_{L}=P_{i n v} T\left\{\sum_{n=0}^{4} A_{n, L}\left[\int_{G} G_{e f f}^{n} f_{G_{e f f}}(G) d G\right]\right\}
$$

\section{B. N-th statistical moments}

Resolution of equations (27) and (28) is easy with the definition of n-th statistical moment of an stochastic variable as $[9,10]$ :

$$
m_{n}=\int_{G} G^{n} f_{G}(G) d G
$$

The first moment, $m_{1}$, is the mean value of the variable, whereas the second moment, $m_{2}$, is related to variance, $\sigma_{G}^{2}$, through $m_{2}=\sigma_{G}^{2}+m_{1}^{2}$. As a nomenclature aid, it is useful to notice that $m_{0}=1$, which is one of the properties of any probability density function.

Equations (27), (28) and (29) lead to:

$$
\begin{aligned}
& E_{d c}=P_{i n v} T\left(A_{1, g} m_{1}+A_{2, g} m_{2}\right) \\
& E_{L}=P_{i n v} T \sum_{n=0}^{4} A_{n, L} m_{n}
\end{aligned}
$$

Finally, AC produced energy estimation results from the substraction of $E_{d c}$ and $E_{L}$ :

$$
E_{a c}=P_{i n v} T \sum_{n=0}^{4} A_{n, a c} m_{n}
$$


where:

$$
\begin{aligned}
& A_{0, a c}=-A_{0, L} \\
& A_{1, a c}=A_{1, g}-A_{1, L} \\
& A_{2, a c}=A_{2, g}-A_{2, L} \\
& A_{3, a c}=-A_{3, L} \\
& A_{4, a c}=-A_{4, L}
\end{aligned}
$$

Since probability density functions of irradiance are frequently unavailable, real computation of statistical moments may be carried out with sampled data using:

$$
m_{n}=\frac{\sum_{G} G_{e f f}^{n}}{N_{s}}
$$

being $N_{s}$ the total number of samples available for calculation.

\section{VALIDATION}

\section{A. Radiation data obtained by the monitoring system}

This so-called "method of statistical moments" has been validated against real performance data from a photovoltaic system, Photocampa, located in Tarragona, installed by ISOFOTON in 2001 [15]. This system is composed with several inverters. Data of one of them, $100 \mathrm{~kW}$ power, has been analysed for this experiment. Available data ranges from $11 / 02 / 2003$ to $14 / 04 / 2005$ with a sampling rate of 1 measure each 10 minutes $\left(N_{s}=15.630\right)$. Solar radiation is evaluated with a calibrated cell at same slope and orientation as the generator plane (consequently, dirtiness and angular losses are included in this measurement). Rest of electrical variables have been acquired by sensors external to the inverters, in order to assure measuring quality. This database has been adequately filtered so only safe samples have been included for computation.

For this system we suppose $\beta=0,475 \frac{\%}{{ }^{C} C}, T O N C=47^{\circ} C, P_{i n v}=100 \mathrm{~kW}, P_{g}^{*}=88 \mathrm{~kW}$, no shadows and constant ambient temperature $T_{a}=25{ }^{\circ} \mathrm{C}$. PV generator power figures correspond to a measurement campaign with a capacitive load [16], carried out after the execution. Inverter parameters, $k_{n}^{i}$, have been obtained adjusting equation (13) to measured data of each inverter, using equations (14), (15) and (16). Equations (18) to (22) allow to calculate $A_{n, L}$.

These intermediate results (table I) together with equations (30), (31), and (33) to (37) with (32), lead to $E_{d c}$, $E_{L}$ and $E_{a c}$ for each inverter. Table II compares these final results with experimental measured energy. Differences between experimental values and those obtained with the method of statistical moments are around $2 \%$, good enough to demonstrate quality of this method.

\section{B. Radiation data from an external measuring system}

Previous validation exercise, using a posteriori radiation values, is not representative of real photovoltaic design practice, where a priori radiation databases are needed. To analyse this situation, real performance data of the FORUM PV Pergola [20], located in Barcelona, is compared against the results of the statistical moments method applied to radiation data from a meteorological station installed in the University of Physics, $10 \mathrm{~km}$. from the PV system. This database contains information from 1991 to 1999 with a sampling rate of 1 measure each 10 minutes. A mean year is constructed, obtaining $N_{s}=8.208$ for calculations. This station provides horizontal radiation values, so a calculation procedure is applied for obtaining effective radiation in the generator plane. Table III summarises which methods have been used.

For this second validation we are analysing performance data from a $125 \mathrm{~kW}$ inverter, feeded by a PV generator with installed power $P_{g}^{*}=138,6 \mathrm{~kW}$, now with constant ambient temperature $T_{a}=20{ }^{\circ} \mathrm{C}$ and again without shadows. Available data ranges from May 2004 to March 2005 with a sampling rate of one measure per minute. Electrical variables have been acquired by sensors included inside the inverters, and compared with external energy meters in order to assure measuring quality. This database has been adequately filtered so only safe samples have 
been included for computation. Rest of calculations follows same steps of Photocampa validation (table I). Energy figures comparison is shown in table II.

Now differences between real data and estimated energy are below $5 \%$, higher than with previous exercise, but still satisfactory because:

- Energy production has been predicted from a radiation database distant in space (10 km.) and in time (5 years). Regarding time, figure 1 shows how annual radiation fluctuates from year to year. For this period, variations near $10 \%$ around mean value happened, which means uncertainty in energy prediction .

- Calculation error occurs with transposing from horizontal radiation (source data) to effective inclined radiation.

- Dirtiness evolution throughout the period has been approximated as a constant.

Table I: Intermediate results using method of statistical moments

\begin{tabular}{|c||c|c||c|}
\hline Parameter & Photocampa & Forum & Units \\
\hline \hline$m_{1}$ & $4,62 \cdot 10^{2}$ & $3,49 \cdot 10^{2}$ & {$\left[W \cdot m^{-2}\right]$} \\
\hline$m_{2}$ & $2,91 \cdot 10^{5}$ & $1,73 \cdot 10^{5}$ & {$\left[W \cdot m^{-2}\right]^{2}$} \\
\hline$m_{3}$ & $2,10 \cdot 10^{8}$ & $10^{8}$ & {$\left[W \cdot m^{-2}\right]^{3}$} \\
\hline$m_{4}$ & $1,62 \cdot 10^{11}$ & $6,46 \cdot 10^{10}$ & {$\left[W \cdot m^{-2}\right]^{4}$} \\
\hline \hline$k_{0}^{i}$ & $2,43 \cdot 10^{-2}$ & $0,5 \cdot 10^{-2}$ & {[]} \\
\hline$k_{1}^{i}$ & $2,72 \cdot 10^{-2}$ & $2,97 \cdot 10^{-2}$ & {[]} \\
\hline$k_{2}^{i}$ & $1,66 \cdot 10^{-2}$ & $0,95 \cdot 10^{-2}$ & {[]} \\
\hline \hline$A_{1, g}$ & $9,02 \cdot 10^{-4}$ & $1,13 \cdot 10^{-3}$ & {$\left[W^{-1} m^{2}\right]$} \\
\hline$A_{2, g}$ & $-1,45 \cdot 10^{-7}$ & $-1,82 \cdot 10^{-7}$ & {$\left[\left(W^{-1} m^{2}\right)^{2}\right]$} \\
\hline \hline$A_{0, L}$ & $2,43 \cdot 10^{-2}$ & $5,02 \cdot 10^{-3}$ & $\square$ \\
\hline$A_{1, L}$ & $2,39 \cdot 10^{-5}$ & $3,38 \cdot 10^{-5}$ & {$\left[W^{-1} \cdot m^{2}\right]$} \\
\hline$A_{2, L}$ & $9,03 \cdot 10^{-9}$ & $6,87 \cdot 10^{-9}$ & {$\left[W^{-1} \cdot m^{2}\right]^{2}$} \\
\hline$A_{3, L}$ & $-1,23 \cdot 10^{-13}$ & $-3,94 \cdot 10^{-12}$ & {$\left[W^{-1} \cdot m^{2}\right]^{3}$} \\
\hline$A_{4, L}$ & $3,31 \cdot 10^{-16}$ & $3,16 \cdot 10^{-16}$ & {$\left[W^{-1} \cdot m^{2}\right]^{4}$} \\
\hline
\end{tabular}

Table II: DC, AC and inverter losses energies comparison

\begin{tabular}{|c||c|c|c||c|c|c|}
\hline \multicolumn{1}{|c||}{} & \multicolumn{3}{c||}{ Photocampa } & \multicolumn{3}{c|}{ Forum } \\
\hline \hline Energy & $\begin{array}{c}\text { Estimation } \\
(\mathrm{kWh})\end{array}$ & $\begin{array}{c}\text { Real Data } \\
(\mathrm{kWh})\end{array}$ & $\begin{array}{c}\text { Difference } \\
(\%)\end{array}$ & $\begin{array}{c}\text { Estimation } \\
(\mathrm{kWh})\end{array}$ & $\begin{array}{c}\text { Real Data } \\
(\mathrm{kWh})\end{array}$ & $\begin{array}{c}\text { Difference } \\
(\%)\end{array}$ \\
\hline \hline$E_{d c}$ & 95.249 & 93.361 & 2,02 & 62.355 & 65.149 & 4,29 \\
\hline$E_{L}$ & 9.677 & 9.623 & 0,44 & 3.011 & 2.900 & $-3,82$ \\
\hline$E_{a c}$ & 85.572 & 83.737 & 2,22 & 59.344 & 62.249 & 4,67 \\
\hline
\end{tabular}

Table III: Calculation procedure for estimation of effective irradiance in the generator plane from horizontal irradiance data

\begin{tabular}{|l|l|}
\hline Step & Method \\
\hline $\begin{array}{l}\text { Decomposition of Global Horizontal Daily } \\
\text { Irradiation into Diffuse and Direct compo- } \\
\text { nents and }\end{array}$ & $\begin{array}{l}\text { Correlation between diffuse fraction of hor- } \\
\text { izontal radiation and clearness index pro- } \\
\text { posed by Collares-Pereira and Rabl [12] }\end{array}$ \\
\hline $\begin{array}{l}\text { Estimation of instantaneous irradiance } \\
\text { from daily irradiation }\end{array}$ & $\begin{array}{l}\text { Ratio of global irradiance to global daily ir- } \\
\text { radiation proposed by Collares-Pereira and } \\
\text { Rabl [12] }\end{array}$ \\
\hline $\begin{array}{l}\text { Estimation of irradiance on inclined } \\
\text { surface from horizontal irradiance } \\
\text { components }\end{array}$ & Method of Hay and Davies [13] \\
\hline Albedo irradiance & $\begin{array}{l}\text { Isotropic diffuse irradiance with reflection } \\
\text { factor equal to 0,2 }\end{array}$ \\
\hline Effects of dirt and angle of incidence & $\begin{array}{l}\text { Equations proposed by N. Martin [14]. For } \\
\text { this validation, a low constant dirtiness de- } \\
\text { gree has been supposed. }\end{array}$ \\
\hline
\end{tabular}




\section{Relevance of statistical moments}

Following equation (32) first to fourth statistical moments are needed for energy production estimation. As already explained, first moment is the mean value of the radiance series, second moment is related to variance, and third and fourth moments give information about skewness and kurtosis, respectively. It is common sense that mean and variance value influence in the final result, but, are really third and fourth moments important in global calculation? Table IV compares AC energy results for Photocampa system, depending on which moments are involved in equation $(32)$.

If only mean value is used, $E_{a c} \simeq P_{i n v} T \cdot\left(A_{0, a c}+A_{1, a c} m_{1}\right)$, and the error is around $3 \%$. It is worth to note that the product $m_{1} \cdot T$ is just the effective incident irradiation. In yearly terms, this value is available in several atlases and web tools [21-23], although a correction factor for angular and dirtiness losses (for example, 5\% to $7 \%$ ) should be included. Even more, this information can be obtained from the annual value of the global horizontal irradiation - which is still a more widely available data - and using some of the various existing analytical methods, which take into account inclination, orientation, reflection and dust losses. For example, in [6] irradiation on the inclined plane is obtained with:

$$
\frac{G(\beta)}{G\left(\beta_{o p t}\right)}=1+4.46 \cdot 10^{-4}\left(\beta-\beta_{o p t}\right)-1.19 \cdot 10^{-4}\left(\beta-\beta_{o p t}\right)^{2}
$$

and optimal inclination can be calculated with:

$$
\beta_{o p t}=3.7+0.69|\phi|
$$

where $\phi$ is the local latitude $\left(\beta, \beta_{\text {opt }}, \phi\right.$ in degrees $)$.

Let's clarify this subject with an example. Yearly average of daily global horizontal irradiation in Sapporo (Japan), $\phi=43^{\circ}$, is $G_{d}(0)=3220 \mathrm{Wh} / \mathrm{m}^{2}$. Using equation $(40), \beta_{o p t}=33.4^{\circ}$, and with equation $(39), \frac{G_{d}(0)}{G_{d}\left(\beta_{o p t}\right)}=0.8526$, so $G_{d}\left(\beta_{\text {opt }}\right)=3776 \mathrm{Wh} / \mathrm{m}^{2}$. With an inclination of $\beta=15^{\circ}, G_{d}(\beta)=0.8942 \cdot G_{d}\left(\beta_{\text {opt }}\right)=3376 \mathrm{Wh} / \mathrm{m}^{2}$, so annual

Figure 1: Evolution of annual horizontal global irradiation from a meteorological station installed in the University of Physics of Barcelona during the period 1991-1999. Year 1996 has been dropped due to errors in the database

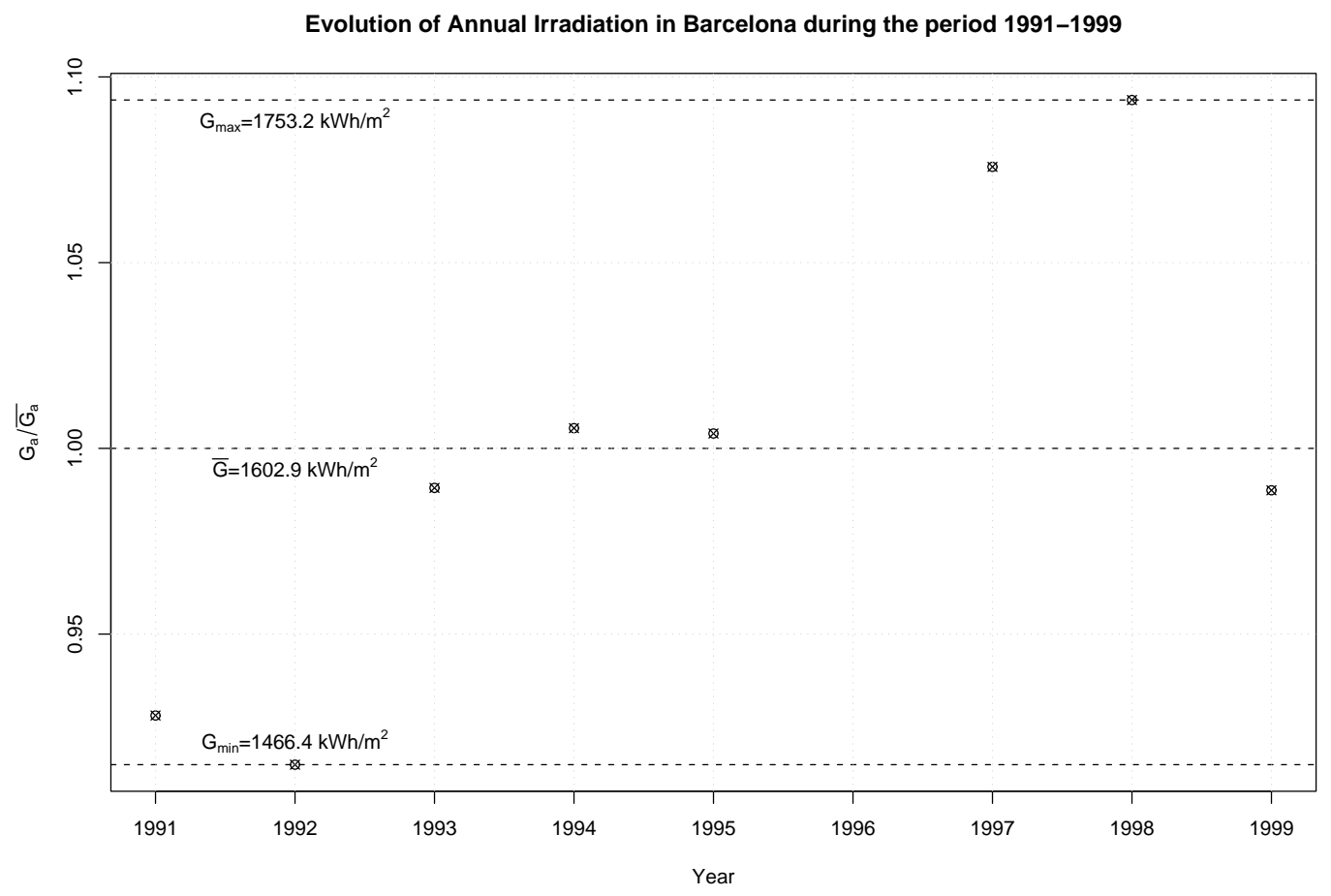


irradiation on the inclined plane is $G_{y}(\beta)=1232.2 \mathrm{kWh} / \mathrm{m}^{2}$. With a correction factor of 0.93 for angular and dirtiness losses, $G_{y, \text { eff }}(\beta)=m_{1} \cdot T=1145.9 \mathrm{kWh} / \mathrm{m}^{2}$. With $T=4380 \mathrm{~h}$ (total diurnal hours per year), $m_{1}=$ $261.6 \mathrm{~W} / \mathrm{m}^{2}$. If a system equivalent to Photocampa would run in Sapporo, assuming $T_{a}=25^{\circ} \mathrm{C}, E_{a c}=100 \cdot 4380$. $\left(-2.43 \cdot 10^{-2}+8.78 \cdot 10^{-4} \cdot 261.6\right)=89.9 M W h$.

If second moment is used in the calculation, error decreases below 1\%. Inclusion of third and fourth moment is almost inappreciable in final result. Consequently equation (32) may be written

$$
E_{a c} \simeq P_{i n v} T \sum_{n=0}^{2} A_{n, a c} m_{n}
$$

which is a way of stating that, despite second order effects associated to wind, spectrum, etc., energy produced by a PV grid-connected system follows a quasi-linear relation with effective irradiation falling in the generator surface.

An interesting benefit of equations (32) to (41) is that they allow long data sequences for a particular location (containing, for example, 4380 hourly values) to be condensed into just 4 - even 2 or 1 - numbers without any important loss of information.

Table IV: Relevance of third and fourth moments

\begin{tabular}{|c|c|c|}
\hline Moments included in calculation & $E_{a c}$ & Error (\%) \\
\hline \hline$m_{1}$ & 84.791 & $2,83 \%$ \\
\hline$m_{1}, m_{2}$ & 81.769 & $-0,84 \%$ \\
\hline$m_{1}, m_{2}, m_{3}$ & 82.503 & $0,05 \%$ \\
\hline$m_{1}, m_{2}, m_{3}, m_{4}$ & 82.458 & - \\
\hline
\end{tabular}

\section{CONCLUSION}

This article develops a proposal of a method of calculation useful for estimation of energy produced by a PV grid-connected system. This method makes use of irradiance-domain integrals and definition of statistical moment. Supposing available first to fourth statistical moments and some basic system parameters, only simple calculations, at the reach of pocket calculators, are enough to estimate AC energy. Differences from real data performance to estimation with this method ranges from $2 \%$ to $5 \%$ depending whether radiation measuring is simultaneous in time and space with the system operation or not. Moreover, it has been demonstrated that contribution of third and fourth moment is not appreciable in total estimation, what makes clear the quasi-linear relation between AC energy and effective radiation. It is not difficult to find studies (for example [24, 25]) that disagree with this assertion, but a detailed comparative analysis will be contributed later.

Anyhow, this statement should be carefully revised when analysing non-linear effects (for example, shadows) which can modify the probability density function of effective radiation, $f_{G_{e f f}}(G)$, and therefore results of equation (29).

\section{Acknowledgements}

These studies have been developed in the context of a R\&D project financed by the "Centro para el Desarrollo Tecnológico Industrial" (CDTI) and the "Programa de Fomento de la Investigación Técnica" (PROFIT).

[1] A. Luque, Photovoltaic Market and Costs Forecast Based on a Demand Elasticity Model, Progress in Photovoltaics 9,pp. 303-312. 2001.

[2] M. Castro, M. Delgado, et al., Grid-connected PV buildings: analysis of future scenarios with an example of Southern Spain, Solar Energy 79, pp.86-95, 2005

[3] F.J. Argul, M. Castro et al. Software modelling of grid-connected photovoltaic buildings, Progress in Photovoltaics 11, pp. 255-273, 2003.

[4] L. Castañer and S. Silvestre, Modelling Photovoltaic Systems using PSpice, Ed. John Wiley\&Sons, 2002.

[5] T. Markvart and L. Castaner, Practical Handbook of Photovoltaics: Fundamentals and Applications, Elsevier Science, First Edition, 2003 
[6] E. Lorenzo, Energy Collected and Delivered by PV Modules, Handbook of Photovoltaic Sciences and Engineering, pp.905967, Edited by A. Luque and S. Hegedus, John Wiley\&Sons, Ltd, 2003.

[7] M. Jantsch, H. Schmidt y J. Schmid. Results on the concerted action on power conditioning and control, 11th European photovoltaic Solar Energy Conference, Montreux, pp. 1589-1592, 1992

[8] Optimizing system planning: Market survey of simulation programs for PV systems, PHOTON International 52, 2003

[9] P.Z. Peebles, Probability Random variables, and random signal principles, Ed. McGraw-Hill, 1980.

[10] D.C. Montgomery and G.C. Runger, Applied Statistics and Probability for Engineers, 3 ed., John Wiley \&Sons, 2003.

[11] R. J. Aguiar, M. Collares-Pereira and J. P. Conde, Simple procedure for generating sequences of daily radiation values using a library of Markov transition matrices, Solar Energy, 40, Pages 269-279, 1988

[12] M. Collares-Pereira and A. Rabl, The average distribution of solar radiation-correlations between diffuse and hemispherical and between daily and hourly insolation values, Solar Energy, 22, Pages 155-164, 1979

[13] J.E Hay and D.C. McKay, Estimating Solar Irradiance on Inclined Surfaces: A Review and Assessment of Methodologies, Int. J. Solar Energy, 3, pp. 203 y ss. 1985

[14] N. Martin and J.M. Ruiz, Calculation of the PV modules angular losses under field conditions by means of an analytical model, Sol Energy Mater. Solar Cells, 70, 25-38, 2001

[15] O. Perpiñán et al., PHOTOCAMPA: PV system integrated into a large car park, 17th PV European Conference, Munich, 2001.

[16] J. Muñoz and E. Lorenzo, Capacitive load based on IGBTs for on-site characterization of PV arrays, Solar Energy, online January 2006.

[17] M. Topic, K. Brecl and J. Sites, Effective efficiency of PV modules under field conditions, Progress in Photovoltaics, available online June 2006.

[18] K. Bücher, Site dependence of the energy collection of PV modules, Solar Energy Materials and Solar Cells, 47, pp 85-94, 1997.

[19] Anuario Meteorológico de Cataluña http://www.gencat.net/servmet/marcs/marcos_historia/marcs_atles.htm

[20] O. Perpiñán et al., Forum Solar: A Large PV Pergola for Forum 2004, 19th PV European Conference, Paris, 2004.

[21] S@tel-light http://www.satel-light.com

[22] PVGIS http://re.jrc.cec.eu.int/pvgis/pv

[23] ESRA http://ww.helioclim.net/esra

[24] S. Ransome and P. Funtan, Why hourly averaged measurement data is insufficient to model PV system performance accurately, 20th PV European Conference, Barcelona, 2005

[25] C. Craggs, E.M. Conway and N. M. Pearsall, Statistical investigation of the optimal averaging time for solar irradiance on horizontal and vertical surfaces in the UK, Solar Energy 68, No. 2, pp. 179-187, 2000 